\title{
The History of Linguistics Matters: Linguistic Relativity and Integral Linguistics
}

\author{
Joseph L. Subbiondo \\ California Institute of Integral Studies, San Francisco, USA
}

\begin{abstract}
By studying the history of a discipline, scholars often discover theories that can be adapted for contemporary linguistics. A notable example is linguistic relativity. It was made popular by Benjamin Lee Whorf in the early to mid 20th century before being dismissed by generative grammarians. This paper will explore the renewal of linguistic relativity starting in the late 20th century, its resurgence with the emergence of interdisciplinary research, and its growth in the current neo-Whorfianism. The response today to linguistic relativity demonstrates that relevant concepts will always have a place in contemporary scholarship.
\end{abstract}

Keywords: linguistic relativity, Whorf hypothesis, interdisciplinary research, integral linguistics, neo-Whorfianism

\section{Introduction}

The history of a discipline matters. Scholars often develop new perspectives by adapting old concepts that have been set aside, overlooked, or even rejected by those subscribing to the dominant theory of the day. A history of linguistic relativity since 1980 has provided a compelling case study of linguists' adapting past ideas to recast a present and future for their discipline. During this period, an interdisciplinary model of linguistics emerged - an "integral linguistics" - that expands traditional linguistics beyond its conventional boundaries by integrating extensive scholarship from related disciplines.

Wilhelm von Humboldt (1767-1835) drew attention to linguistic relativity in the late 18th and early 19th century and Franz Boas (1858-1942) and Edward Sapir (1884-1939) explored it in the 20th century. Benjamin Lee Whorf (1897-1941) advanced it in the early to mid-20th century and his work continued to be the point of departure for research on linguistic relativity. Generative-transformational theory dominated linguistics soon after Whorf's death and its proponents rejected any notion of linguistic relativity. However, in the late 1980s, several linguists engaged interdisciplinary research in exploring the interconnectedness of language, culture, and consciousness and initiated renewed consideration of linguistic relativity.

The radical issue of the long-standing debate regarding linguistic relativity has been succinctly summarized by Peter Carruthers as "whether thought is independent of language, or whether our thinking, on the contrary, necessarily requires or involves natural language" (1996, p. 2). The former, he labeled communicative conception in which language facilitates communication but not thinking; and the latter, cognitive conception in which language facilitates thinking. In light of recent developments in cognitive studies in several disciplines, including linguistics, I will focus on the notion of cognitive conception.

Joseph L. Subbiondo, president emeritus, M.A., California Institute of Integral Studies, San Francisco, USA. 
My brief history is organized around three themes: first, a reconsideration of Whorf's principle of linguistic relativity; second, the emergence of linguistic relativity in interdisciplinary research; and third, the growth of "neo-Whorfianism" (McWhorter, 2014), a contemporary version of linguistic relativity supported by linguists and cognitive psychologists as well as by scholars in consciousness studies, cultural anthropology, and neurobiology. The themes are interrelated as scholars who advance theories of linguistic relativity typically draw on histories of their disciplines as well as the results of interdisciplinary research projects (see Subbiondo, 2015).

\section{Theme One: Reconsideration of Whorf's Principle of Linguistic Relativity}

In the mid 20th century, linguistic relativity was often rejected because of a Western bias. For example, Roger Brown (1958) dismissed Whorf's work because it was based on non-Western languages. He failed to imagine that speakers of French might think differently than speakers of German. He wrote in Words and Things (1958):

It is (Whorf's) belief that each language embodies and perpetuates a world view... however Whorf's documentation of his view comes from the American Indian tongues, chiefly Hopi. Perhaps linguistic relativity is true for peoples speaking totally unrelated languages, but it may have no application within the Indo-European orbit to which we and the other western nations belong. (Brown, 1958, p. 230)

We see the first stages of renewed interest in linguistic relativity in the work of George Lakoff and Mark Johnson (1980) who acknowledged in Metaphors We Live By: "Our observations about how a language can reflect the conceptual system of its speakers derive in great part from the work of Edward Sapir, Benjamin Lee Whorf, and others who have worked in this tradition" (p. xi). In Women Fire, and Dangerous Things (1987), Lakoff, in sharp contrast to Brown, praised Whorf as "the most interesting linguist of his day" (p. 330):

One all-important thing should be remembered about Whorf. He did most of his work at a time when Nazism was on a rise in Europe and jingoism was prevalent in America... white people were assumed... to be more intelligent than people with skin of other colors. Western civilization was assumed to be the pinnacle of intellectual achievement: other civilizations were considered inferior. "Culture" meant European and American culture, not Hopi culture or Balinese culture... it was even thought that Western languages were "advanced" and non-western languages were "primitive". The very idea that "uneducated" Indians, who were still considered savages by many, could reason as well as educated Americans and Europeans was extraordinary and radical. The notion that their conceptual system better fit scientific reality - that we could learn from them-bordered on the unthinkable.

Whorf was not only a pioneer in linguistics. He was a pioneer as a human being. That should not be forgotten. (Lakoff, 1987, p. 330)

Lakoff asserted his support of cognitive conception: "I am convinced by Whorf's arguments that the way we use concepts affects the way we understand experience...” (1987, p. 335).

Emily Shultz (1990) summed up the experience of many linguists in the late 1980s:

From the time I first encountered them, the essays of Benjamin Lee Whorf impressed me as exciting, puzzling, and ultimately frustrating. I studied them, accepted conventional explanation about what was wrong with them, and went on to other things. In 1985, however, while preparing the chapter on language for a cultural anthropology book, I had an opportunity to read Whorf again, at length and closely. This led me to question the traditional interpretations of Whorf's work... (Shultz, 1990, p. xi) 
In addition to Shultz's reconsideration of Whorf's work, John Lucy (1992) and Penny Lee (1996) wrote impressive biographical studies in the 1990s in which they convincingly pointed out that Whorf's critics misinterpreted his work. Lucy (1992) traced linguistic relativity from Humboldt to Whorf whom he claimed, "went well beyond Boas and Sapir" (p. 62). He noted that the "very real interdisciplinary nature of [linguistic relativity] represents a significant obstacle given the present state of research training, which sharply limits the acceptable topics and methods in most social science fields" (pp. 3-4). Lucy maintained that ideas are often rejected not on their merits but on the inability of scholars to appreciate their worth. He noted that an idea can be ahead of its time, supporting that histories of disciplines matter.

In her study of Whorf, Lee (1996) commended Whorf for his interdisciplinary research: She noted that "References to his ideas about the relationships between language, mind, and experience are often made in texts written for students of language, psychology, education, intercultural relations, and philosophy" (p. xiii). Unlike Whorf's critics, Lee recognized that his education in physics and chemistry gave him perspectives different that those traditionally educated in linguistics. Lee, like Lucy, contended that Whorf's work was rejected in the mid 20th century because it was ahead of his time. Lee asserted that Whorf's "theories about linguistic thinking developed more than a half century ago anticipated in several respects ways of talking and thinking about language in cognition which are only now gaining currency in cognitive science" (p. xvii).

Lee's comment serves as an excellent transition to our second theme: linguistic relativity in interdisciplinary research.

\section{Theme Two: The Emergence of Linguistic Relativity in Interdisciplinary Research}

Interdisciplinary integration is well represented in two collections of essays inspired by academic symposia and published by leading university presses: Rethinking Linguistic Relativity (1996), edited by John Gumperz and Stephen Levinson and published by the Cambridge University Press; and Language in Mind: Advances in the Study of Language and Thought (2003), edited by Dedre Gentner and Susan Goldin-Meadow and published by the MIT Press.

Gumperz' and Levinson's collection grew out of the 1991 Wenner-Gren Symposium 112 held in Jamaica and entitled Rethinking Linguistic Relativity. The program focused on the following: linguistic determinism, universality and variation in language and culture, interpretation in cultural context, and the social matrix. For the most part, the contributors were faculty members from several academic departments including psychology, anthropology, and linguistics at prominent research universities in the US and Europe including University of California, Berkeley; University of Chicago; and Stanford University.

The editors recognized the importance of linguistic relativity in several disciplines as well as acknowledged the validity of the debate regarding communicative vs. cognitive communication. They indicated:

Every student of language or society should be familiar with the essential idea of linguistic relativity, the idea that culture, through language, affects the way we think, especially perhaps our classification, of the experienced world. Much of our experience seems to support some such idea... On the other hand, there is a strand of robust common sense that insists that a stone is a stone whatever you call it, that the world is a recalcitrant reality that imposes its structure on our thinking and our speaking and that the veil of linguistic difference can be ripped aside with relative ease. (Gumperz \& Levinson, 1996, p. 1) 
The topics of this paper are all represented in the collection. Stephen Levinson documented that "the rise of cognitive sciences has caused a sea-change in our approach to issues concerning the relation between language, culture, and thought" (p. 177). Dan Slobin sketched a history of linguistic relativity beginning with Humboldt who recognized that as language and thought are inseparable, there are as many world-views as there are languages. Slobin, like we will see in Andresen (2014), moved from a study of static "Thought and Language" to dynamic "Thinking for Speaking". Pascal Boyer (1996) argued that Whorf has been misinterpreted by his critics "as the originator or champion of an extreme form of cultural relativism, without much consideration of his original observations and hypotheses" (p. 203).

Gentner's and Goldin-Meadow's collection grew out of a 1998 symposium on language and thought sponsored by the Cognitive Science Program at Northwestern University. The editors noted, "Recently things have changed. After decades of neglect, language-and-cognition has again become an arena of active investigation" (Gentner \& Goldin-Meadow, 2003, p. 6). Like Gumperz and Levinson, they argued that their collection is not intended to settle the debate of linguistic relativity, but to inspire study of it. The contributors also represent several disciplines including linguistics, psychology, cognitive science, education, and anthropologyat leading research universities such as Brown, Harvard, Stanford, Duke, and University of California, Berkeley.

Gentner and Goldin-Meadow identified three areas pertaining to linguistic relativity that reflect much of the direction of the scholarship in the late 90's: first, documenting that speakers of different languages often have different world-views; second, recognizing that language is critical in developing cognition; and third, moving from studying color only to exploring other human domains.

The contributors often support their claims by referring to a history of linguistics. For example, Mutsumi Imai (Keio University) and Reiko Mazuka (Duke University) in their essay Reevaluating Linguistic Relativity (2003) outlined the history of the dominant views of language universals and linguistic relativity. Based on their research on speakers of Japanese and English, they conclude, "Human cognition is neither absolutely universal nor absolutely diverse" (Imai \& Mazuka, 2003, p. 461).

This "neither one nor the other, but both" view is an excellent transition to our third theme: The Growth of Neo-Whorfianism.

\section{Theme Three: The Growth of Neo-Whorfianism}

In The Unfolding of Language (2005), Guy Deutscher, challenged the innate model of Noam Chomsky in favor of an evolutionary model. He built on this theme in his Through the Language Glass: Why the World Looks Different in Other Languages (2010) by posing a contemporary version of linguistic relativity. While rejecting Whorf's specific arguments, Deutscher (2005) maintained, "That the notion that language can influence thoughts should not be dismissed out of hand... It is only by understanding where [the proponents of] linguistic relativity went astray that we can turn a different way" (p. 131). He commended Humboldt, Boas, Sapir, and Whorf for introducing scholars to non-Indo-European languages, as Western scholars had considered them irrelevant. He noted that missionaries were among the first Westerners to study non-Indo-European languages, but they tended to describe them in traditional grammar. Deutsch proposed a linguistic relativity that supports Whorf's premise; but using dissimilar data, he arrived at different conclusions. 


\section{LINGUISTIC RELATIVITY AND INTEGRAL LINGUISTICS}

In The Language Hoax: Why the World Looks the Same in Any Language (2014), John McWhorter opposed Deutsher's position as evident in the title. He described his book as a "manifesto" against a growing "Neo-Whorfianism":

I will oppose an idea about language that took hold among certain academics starting in the 1930s, and of late has acquired an unseemingly amount of influence over public discussion as well. This is the idea that people's languages channel the way they think and perceive the world. (McWhorter, 2014, p. ix)

McWhorter conceded that: "Crucially, a connection between language and thought does exist" (p. xiv) and he recognized that Neo-Whorfians have a "more measured approach" (p. xiv) than Whorf. He noted that "[their] experiments are clever and elegant, and only the most rabid skeptic could deny that their work has shown a connection between language and thought" (p. xiv).

McWhorter argued that differences of worldviews in languages are interesting but insignificant. In his view, Neo-Whorfians disparaged billions of human beings as well as created "cartoonish perspectives about ourselves" (p. xix) by overstating links of particulars languages to worldviews. Nonetheless, McWhorter accepted connection between language and thought:

I deny not that language and culture are linked, I question a particular kind of linkage between the two, in which grammatical features and vocabulary configurations that no native speaker would consider at all remarkable... condition a way of processing life. (McWhorter, 2014, p. 168)

McWhorter positioned himself as one advancing a position that neither supports Chomsky's concept of a "Language Acquisition Device" nor "disrespects the massive body of work on linguistic anthropology, cognitive linguistics, and the philosophy of language" (pp. 166-167). In short, he maintained a "neither one nor the other but both" position.

In Imprisoned in English: The Hazards of English as a Default Language (2014), Anna Wierzbicka defined language as a conceptual cage and she recognized that her definition is subject to sharp criticism if not outright dismissal by linguists. She reiterated the claim by Humboldt that to think outside one's culture, it is often necessary to learn the language of that culture. She stated: "It has often been said (following Humboldt) that to learn to think outside the mold of one's native language one needs to move into another language" (p. xi). She pointed out that "In a globalized world in which English has become, effectively, the first global lingua franca, it is increasingly easy to forget that the whole world doesn't think in English" (Wierzbicka, 2014, p. 64). Wierzbicka referred to Vivian Cook (2009) who suggested that physical and mental worlds are "provided up by the words of our language" (p. 27). Cook drew on many disciplines in her cause to preserve the worldviews of many languages.

Julie Tetel Andresen, in Linguistics and Evolution: A Developmental Approach (2014), examined all of the themes in this paper: the relevance of disciplinary history, a contemporary version of linguistic relativity, an integral linguistics, and a radical expansion of a discipline. Andresen intended to

Introduce linguists and language theorists to a constructivist account of our subject matter in order to open a path to the discipline's future... She proposes a linguistics inspired by Darwin rather than Descartes that would lead the discipline to "to understand our subject matter in the fullness of the biological, evolutionary, neurological, psychological, and sociological research now available to us. (Andresen, 2014, p. 30) 
Andresen (2014) maintained "the shift from noun to verb, from language as an abstraction of some sort to languaging as an activity helps to facilitate a welcome shift in point of view" (p. 31). She argued that 21 st century linguists should draw on interdisciplinary research instead of asking "what is language" and "how do living beings become languaging living beings". Andresen included the work of scholars not typically included in books on linguistics (for example, Humberto Maturana, Francisco Varela, and Paul Eckman) who contribute much to our understanding of languaging. Moreover, Andresen drew on her knowledge of the history of linguistics to reframe its present and future, expand its boundaries, and increase its relevance (see Subbiondo, 2016).

\section{Conclusion}

Recently, Oxford University Press has announced its publication, the Journal of Language Evolution, which reflects not only the trends in interdisciplinary scholarship in general, but also exemplifies "integral linguistics" in particular. The editors state that the journal will be the only scholarly journal exclusively devoted to research relevant to language origins and evolution. It is highly interdisciplinary and covers theoretical, computational, database-driven, and experimental work emerging from:

(1) Linguistics;

(2) (Neuro-) cognitive sciences;

(3) Psychology;

(4) Anthropology;

(5) Biology;

(6) Evolutionary theory;

(7) Computer sciences;

(8) Philosophy;

(9) Other relevant disciplines.

C. S. Lewis (1898-1963) and Own Barfield (1898-1997) jointly coined the term chronological snobbery to name, in Lewis' words, the "uncritical acceptance of the intellectual climate common to our own age and the assumption that whatever has gone out of date is on that account discredited" (p. 207). Lewis advised:

You must find why it went out of date. Was it ever refuted (and if so by whom, where, and how conclusively) or did it merely die away as fashions do? If the latter, this tells us nothing about its truth or falsehood. From seeing this, one passes to the realization that our own age is also "a period", and certainly has, like all periods, its own characteristic illusions. They are likeliest to lurk in those widespread assumptions which are so ingrained in the age that no one dares to attack or feels it necessary to defend them. (Lewis, 1955, pp. 207-208)

The history of linguistics matters lest we fall victims of chronological snobbery.

\section{References}

Andresen, J. T. (2014). Linguistics and evolution: A developmental approach. Cambridge: Cambridge University Press.

Boyer, P. (1996). Cognitive limits to conceptual relativity: The limiting-case of religious ontologies (pp. 203-219). Cambridge:

Cambridge University Press.

Brown, R. (1958). Words and things. New York: The Free Press.

Carruthers, P. (1996). Language, thought and consciousness. Cambridge: Cambridge University Press.

Cook, V. (2009). All in a word. London: Melville House. 


\section{LINGUISTIC RELATIVITY AND INTEGRAL LINGUISTICS}

Deutscher, G. (2005). The unfolding of language: An evolutionary tour of mankind's greatest gift. New York: Henry Holt and Company.

Deutscher, G. (2010). Through the language glass; Why the world looks different in other language. New York: Henry Holt and Company.

Gentner, D., \& Goldin-Meadow, S. (Eds.). (2003). Language in mind: Advances in the study of language and thought. Cambridge, MA: MIT Press.

Gumperz, J., \& Levinson, S. (Eds.). (1996). Rethinking linguistic relativity. Cambridge: Cambridge University Press.

Imai, M., \& Mazuka, R. (2003). Reevaluating linguistic relativity: Language-specific categories and the role of universal ontological knowledge in the construal of individuation. Cambridge, MA: MIT Press.

John, A. L. (1992). Language diversity and thought: A reformulation of the linguistic relativity hypothesis. Cambridge: Cambridge University Press.

Johnson, M., \& Lakoff, G. (1980). Metaphors we live by. Chicago: University of Chicago Press.

Lakoff, G. (1987). Women fire, and dangerous things: What categories reveal about the mind. Chicago: The University of Chicago Press.

Lee, P. (1996). The Whorf theory complex: A critical reconstruction. Amsterdam: John Benjamins.

Lewis, C. S. (1955). Surprised by joy. New York: Harcourt Brace.

McWhorter, J. H., (2014). The language hoax: Why the world looks the same in any language. Oxford: Oxford University Press.

Rollins, P. C. (1980). Benjamin Lee Whorf: Lost generation theories of mind, culture, and religion. Ann Arbor MI: University Microfilms International for Popular Culture Association.

Schultz, E. A. (1990). Dialogue at the margins: Whorf, Bakhtin, and linguistic relativity. Madison: University of Wisconsin Press.

Subbiondo, J. (2015). Language and consciousness: The perennial relevance of Benjamin Lee Whorf. Language and History, 58, $55-63$.

Subbiondo, J. (2016). Review of Andresen. Language and History, 59, 75-78.

Wierzbicka, A. (2014). Imprisoned in English: The hazards of English as a default language. Oxford: Oxford University Press. 